\title{
Retraction Note: Brace classification study group (BCSG): part one - definitions and atlas
}

Theodoros B. Grivas', Jean Claude de Mauroy², Grant Wood ${ }^{3}$, Manuel Rigo ${ }^{4}$, Michael Timothy Hresko ${ }^{5}$, Tomasz Kotwicki ${ }^{6}$ and Stefano Negrini ${ }^{7,8}$

\section{Retraction Note}

The Publisher has retracted this article [1], as it is unclear whether written informed consent was obtained from some patients to publish their images in an Open Access journal. The article is no longer available online in order to protect the privacy of the individuals. GW, $\mathrm{SN}$, JCDM and TG disagree with this retraction. MR, MTH and TK did not state whether they agreed or disagreed with the retraction.

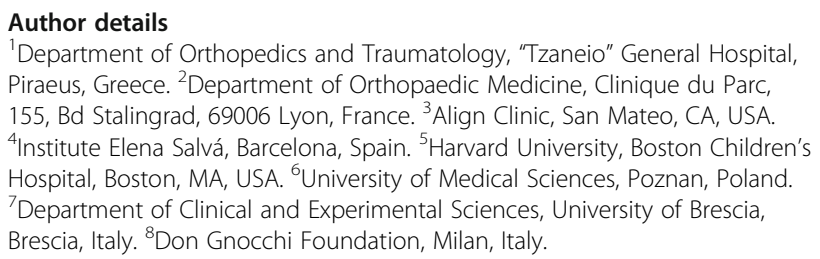

\section{Reference}

1. Grivas TB, de Mauroy JC, Wood G, Rigo M, Hresko MT, Kotwicki T, Negrini S.

Brace classification study group (BCSG): part one - definitions and atlas.

Scoliosis Spinal Disord. 2016;11:43.

\footnotetext{
*Correspondence: demauroy@aol.com

${ }^{2}$ Department of Orthopaedic Medicine, Clinique du Parc, 155, Bd Stalingrad, 69006 Lyon, France
} 